\title{
BM] Global Health Tailored support for national NCD policy and programme implementation: an over-looked priority
}

\author{
Angela Jackson-Morris (i) , Rachel Nugent
}

To cite: Jackson-Morris A, Nugent R. Tailored support for national NCD policy and programme implementation: an over-looked priority. BMJ Global Health 2020;5:e002598. doi:10.1136/ bmjgh-2020-002598

Handling editor Seye Abimbola

Received 6 April 2020

Revised 12 June 2020

Accepted 28 June 2020

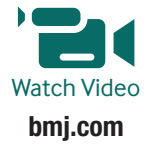

Check for updates

(C) Author(s) (or their employer(s)) 2020. Re-use permitted under CC BY-NC. No commercial re-use. See rights and permissions. Published by BMJ.

Center for Global NonCommunicable Diseases, Research Triangle Institute, Seattle, Washington, USA

Correspondence to Dr Angela Jackson-Morris; ajackson-morris@rti.org

\section{ABSTRACT}

Many low-income and middle-income countries (LMICS) are unlikely to achieve Sustainable Development Goal 3.4 to reduce premature deaths from non-communicable diseases (NCDs) by one-third by 2030 . For some, the prospect is receding: between 2010 and 2020, the decline in premature deaths for the major NCDs slowed compared with the prior decade. Barriers to implementing effective strategies are well known, yet the value of tailored technical support to countries has been overlooked and downplayed. Tailored technical support is specialist guidance for country-specific application of technical tools, and capacity enhancement when needed, that enables an LMIC to advance its NCD priorities and plans. We present a model identifying pivotal junctures where tailored technical support can help surmount implementation obstacles. We draw on our experience preparing NCD investment cases with health ministries, development partners and technical agencies. National investment cases produce evidence based, locally tailored and costed packages of NCD interventions and policies appropriate to national needs and circumstances. They can include analysis of financing needs and point towards sustainable funding mechanisms. Enhancing the NCD-specific knowledge of government and Civil Society Organization leads can capitalise on existing expertise, aid integrative health system developments and unlock capabilities to use global tools and guidance. Investment cases form a platform to develop or review NCD plans and (re)prioritise action, then apply implementation science to trouble-shoot obstacles. Partnering national stakeholders with technical support in this process is critical to develop and implement effective NCD strategies.

Low-income and middle-income countries (LMICs) experience many barriers in carrying out their non-communicable diseases (NCDs) strategies. This is evident in the deceleration that has occurred in reducing premature mortality from major NCDs since $2010^{1}$ and is painfully manifest in the conclusions of the latest WHO national country capacity survey. ${ }^{2}$ This survey found that generally integrated NCD policies were of inadequate breadth, 'Best Buy' interventions vastly underused, NCD surveillance systems insufficiently robust,

\section{Summary box}

Barriers to implementing effective noncommunicable disease (NCD) strategies are well known, yet the value of tailored technical support to countries has been overlooked and downplayed.

- We present a model of steps focused at key NCD implementation junctures that often require tailored technical support to ensure progress.

- National investment cases provide countries with evidence based, locally tailored and costed packages of NCD interventions and policies appropriate to national needs and circumstances.

- Tailored technical support can empower national stakeholders to put investment cases into operation by partnering local expertise with specialist guidance for specific policies and programmes, using implementation science to surmount implementation obstacles and building national NCD capacity.

lack of clinical guidelines for leading NCDs, cancer-screening programme reach was often inadequate, essential NCD technologies and medicines remained widely unavailable, and palliative care was sparse. These weaknesses predated the COVID-19 pandemic, however, Severe Acute Respiratory Syndrome Coronavirus 2 (SARS-CoV-2) brutally exposed the limitations of many countries' health systems as well as the significant vulnerability of the large numbers of people living with NCDs that insufficient action has created. Key barriers to NCD strategy implementation have been well articulated in the last decade. The 2020 WHO Independent High-Level Commission on NCDs highlights the need for political support to advance the NCD agenda, and need to develop sustainable financing for programmes, service delivery and human resources. ${ }^{3}$

In a brief sentence in this report, some commissioners highlighted the need for more tailored support to LMIC to implement NCD strategies. We contend that tailored technical support is actually pivotal to enable 


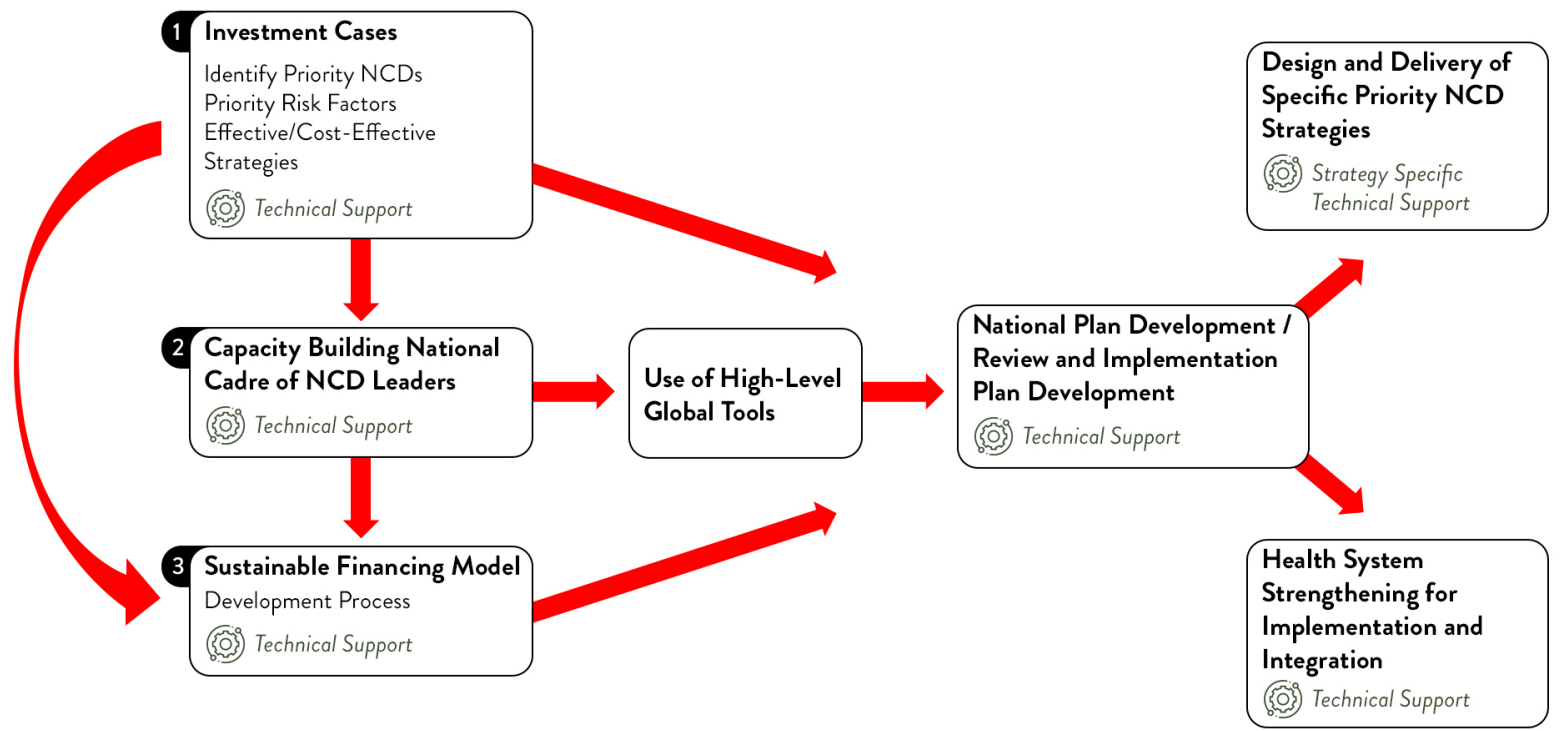

Figure 1 Pivotal points for tailored technical support to support NCD implementation. NCD, non-communicable disease.

the Report's more prominent recommendations to be put into practice, and provision of such support requires serious consideration-and urgently-if we are collectively to move closer to achieving Sustainable Development Goal (SDG) 3.4 in 10 years time.

The terms 'technical support'/'technical assistance' are widely used in health and development although definitions and emphases vary. Common features are external provision of specialist knowledge, partnership with local stakeholders and capacity-building. Tailored technical support is meant here as provision of specialist guidance to support country-specific application of technical tools, and capacity enhancement when needed, to enable an LMIC to advance its NCD priorities.

\section{IDENTIFYING THE PIVOTAL POINTS TO STRENGTHEN NATIONAL IMPLEMENTATION}

Drawing on our experience preparing NCD investment cases and designing NCD strategies and implementation by partnering with health ministries in multiple countries, we present a model to suggest how national NCD implementation may be strengthened. The model (figure 1) identifies a series of critical components that precede effective implementation: working with national stakeholders to select the most effective and cost-effective policy and programme priorities for a specific national context; identifying how to fund these sustainably; ensuring the system has capacity to lead and deliver the priorities; reviewing/renewing national strategy to reflect the chosen priorities; and creating a costed, actionable implementation plan. We propose that providing tailored technical support at these critical junctures when needed, working in partnership with national stakeholders, can galvanise NCD implementation.

The components may be viewed as steps that can be applied sequentially or the model can identify the missing components in a specific context where some are already in place. Thus, a country may use an investment case to review and reprioritise an existing strategy; some countries may have stronger NCD stakeholder capacity and may not need to address this; some may have sustainable funding mechanisms under development yet can beneficially align these to the newly identified priority interventions and revised strategy. In this way the model may be flexibly used, recognising that LMICs are at different starting points and relating to their particular circumstances and contexts. For many countries, an investment case is the starting point.

\section{THE IMPACT OF NCD INVESTMENT CASES}

An investment case uses economic and political analysis to provide countries with an evidence-based agenda for implementing NCD policies that provide best valuefor-money and is feasible in that country. The process of conducting an investment case has been described elsewhere $^{4}$ and involves careful review of existing NCD programmes and policies, discussions with national stakeholders to determine how to augment existing programmes in scale and scope, costing these and calculating return on investment-for population health and the national economy. Each step entails detailed discussions with the Ministry of Health and, importantly, the other ministries that have a stake in the results in relation to the economy, agriculture, industry and education. Civil society and private stakeholders are also engaged, collectively providing an understanding on how to align interests and take forward the priority actions. This inclusive process is a key for establishing credibility and laying the groundwork for policy and delivery to evolve.

The impact of individual investment cases varies from country to country and can be hard to measure and harder to attribute. Testimonials from policy-makers who have commissioned and used investment cases, as well as the large backlog of country requests for investment 
cases, lends authenticity to their value. ${ }^{56}$ Notably, many country requests for investment case support have been made but are yet unfunded. ${ }^{7}$ While not every investment case results in immediate or attributable impact, a growing set of examples shows that investment cases can be game-changing to obtain political 'buy-in' and can catalyse multisectoral dialogue on funding solutions. ${ }^{568}$ The evidence from these experiences is that investment cases can catalyse a cascade of national actions such as expanding existing service coverage or implementing new prevention policies. The Republic of Georgia demonstrates how a well-timed investment case can unblock policy action. ${ }^{9}$ In 2017, the Health Ministry was able to introduce the results of a pilot tobacco control investment case into debate over stalled tobacco control legislation. After the investment case was presented the Georgian Parliament agreed on multiple policy changes to reduce tobacco use in the country. Similarly, investment case results were cited in the tobacco control legislation presented to the Armenian Parliament. ${ }^{10}$

Other times the results do not lead directly to legislation but generate interest from advocacy groups and ministries of finance and advances dialogue about the implementation gaps. An example of such awarenessraising comes from the 2019 Samoan tobacco control investment case. ${ }^{11}$ During the Cabinet briefing on the investment case findings, the prime minister directed the minister of finance to immediately raise tobacco taxes. In Kenya, a recently completed NCD investment case drew attention to the high price tag of increasing NCD treatment coverage. ${ }^{12}$ As for many countries, action on their investment case recommendations now awaits an accompanying funding strategy.

\section{FROM INVESTMENT CASE TO NCD IMPLEMENTATION}

An investment case coalesces stakeholders, creates a sense of urgency and fosters 'buy in', and identifies clear investment priorities. These are prerequisites to achieving sustainable funding for NCD strategy implementationwhether from the ministry of finance or external sources. An investment case quantifies the health and economic benefits of implementing NCD prevention and control, yet those results are theoretical without a financing plan to show policymakers and development partners how the strategies can be realised. The financing plan assesses the prospects for generating additional funding from the domestic budget, whether through revenue growth such as higher taxes or resource reallocation, and possible innovative financing sources, such as development bonds or social investment partnerships. The choice of financing mechanisms may be constrained for many low-resource countries and must be determined by responsible national financial officials in line with their development strategies.

But once the NCD investment case is in hand, priority interventions are agreed, and financing is assured, how is effective implementation achieved?
The WHO Global Coordinating Mechanism Working Group on Financing for NCDs developed a tool to assist countries to assess options, yet national capacity to employ this may be stymied without specialist guidance. ${ }^{13}$ Unexpected knowledge gaps can become major impediments if data and skills are unavailable in-country. Such gaps commonly emerge around data analysis, programme costing, budgeting, fiscal and legal policy formulation, demand forecasting, procurement of medical supplies and resource mobilisation. These policy and programme development components require specialised technical skills and can be provided through tailored technical support alongside capacity development so functions can be sustained as programmes mature. Figure 1 shows the linked foundations of effective NCD policy and programme implementation: evidence-based priority setting, strengthening NCD-specific understanding among stakeholders, and ensuring recommended actions can be funded. Each step may require targeted technical support.

For example, a 2017 investment case developed by the Jamaican government with support from the United Nations Development Program (UNDP) examined the return on investment from scaling up NCD clinical interventions and implementing or intensifying prevention policies. ${ }^{4}$ The results showed a potential saving of US $\$ 640$ million and 6600 lives in Jamaica between 2017 and 2032 from implementing the intervention package. This analysis spurred an immediate response from the government's top echelons to implement the NCD programme to accelerate their ambitious economic growth targets. The experience highlighted specific knowledge and skill gaps that had hitherto hindered the Health Ministry from achieving high level policy attention, despite having an NCD strategy and strong inter-governmental apparatus. Gaps had included lack of costing for NCD programme components, need for greater interministry coordination (promptly acted on following the investment case), and greater awareness of the contribution that improved health would make to economic goals.

Until the current pandemic, the links between communicable and NCDs had been overlooked by many global and national health officials, and there is now urgency to determine how to protect people with NCDs and to create stronger population resilience. Investment cases can assist governments by identifying synergies between addressing chronic disease and pandemic resilience, such as health system strengthening measures to ensure services to treat and manage NCDs functioning during pandemics, averting excess NCD mortality and acute admissions. This evidence can then be used to identify sustainable financing mechanisms.

\section{STRENGTHENING NATIONAL NCD CAPACITIES}

Global guidelines, protocols and tool-kits offer highquality support to national NCD planning. ${ }^{14}{ }^{15}$ Yet it is a leap of faith to envisage that managers can take these 'off 
the shelf' and apply them, even when there is high-level 'buy-in' to address NCDs, or that civil society organisations can identify how they can contribute. This is evident from the increased number of NCD plans that sit in place alongside a low level of health system readiness to deliver policies, programmes and services. ${ }^{14}{ }^{16}$ Ironically, given the scarcity of NCD funding, bottlenecks are created whereby available NCD funds remain unspent.

Growth in the number of NCD-trained national health and policy professionals is encouraging. Some MICs offer NCD specialist training in academic and workforce curricula. Yet an NCD skill deficit is common and NCD departments are often still small and pulled in many directions. The current paradigm must shift from: 'I'm a [HIV/maternal health person] and new to NCDs', to each LMIC having a cadre of national officers confident in their NCD expertise. Adding this to their experience in the existing (dominant) priorities, such as communicable disease, maternal and reproductive health, will be a major step towards health system integration solutions. Empowering civil society as partners in the NCD agenda is a vital complement to this.

Strengthening national NCD capacity is a mediumterm goal. Just as with the HIV/AIDS pandemic and COVID-19, there is a critical need to support countries while health crises are underway. National stakeholders (government, civil society and private sector) collectively possess the strongest understanding of their context, a wealth of data and crucially-staff, policy-makers and politicians to lead action. Even where national NCD capacity is stronger, provision of technical support on the policy, system and programmatic mechanisms that can address specific conditions and risk factors can enhance and accelerate progress and reduce health and economic losses.

\section{COPRODUCTION OF NATIONALLY OWNED AND LED OUTCOMES}

Much has been and can further be learnt from earlier experience in collectively advancing global and national health. Best results come when national stakeholders are 'in the driver's seat' with tailored technical support on board as mechanic/navigator, providing specific assistance to facilitate an effective journey. Both national stakeholders and external technical experts are needed. For example, it has been useful to partner government economists and lawyers with global counterparts who specialise in specific risk factors or conditions to develop fiscal and regulatory measures that are resistant to challenges from global commercial and industrial interests. Such collaborations have been notable in tobacco control, ${ }^{17}$ partly owing to the complex, globalised legal, fiscal and commercial influences on the issue at national level, but also because funders recognised unmet need among national governments and prioritised technical assistance and national capacity building. ${ }^{18}$

Global specialists can also introduce new techniques or technologies to build national capacity to apply these to
- Tobacco economic modelling specialists worked with national health, economic, financial and statistical staff and policymakers to develop a taxation model to reduce tobacco consumption while accounting for national revenue needs and community acceptance.

- Social marketing expertise gathered local stakeholder views and understanding to design demand measures for non-sugar beverages (NSBs). This complemented an on-island health and retail / importer partnership to develop NSB supply, and the government-led strengthening of sugar-sweetened beverage taxation.

- Specific legal expertise relating to tobacco control legislation ensured that the islnd-led process to strengthen tobacco control legislation would be legally robust.

- Behavior change specialists delivered a training program to embed motivational approaches to enhance the capacities of health staff for facilitating behavior changes. This built upon and was tailored to health service development of brief interventtion and NCD clinics.

Figure 2 Tailored technical support in partnership for NCD policies and programmes in St Helena 2018-2019. NCD, non-communicable disease.

NCDs. Figure 2 provides an example of this synergistic partnership in relation to NCD policies and programmes developed by the St Helena Government in 2018-2019. Escalating NCD prevalence and cost of treating NCDs on the island and evacuating emergency and complex patients for care overseas generated the political will to reorient bilateral funding towards NCDs. Significant value was added by partnerships that married local contextual expertise with solid evidence from other sources and highly specific support to co-produce solutions to what would otherwise be implementation challenges. This illustrates the 'Design and Delivery of Specific NCD Priority Strategies' and 'Health System Strengthening for Implementation and Integration' components of figure 1

\section{IMPLEMENTATION SCIENCE: A TOOL TO IDENTIFY CONTEXT- SPECIFIC SOLUTIONS}

The model we have put forth to move from investment cases and sustainable financing development to NCD strategy development/review and implementation planning can be informed by using an implementation science framework. Implementation science addresses the need to develop, test, evaluate and retest the interventions and processes that constitute an NCD programme. Knowledge will emerge about 'what works' and should be shared widely to aid effective delivery. There are various implementation science models, with the shared aim of improving knowledge in context to support effective implementation. ${ }^{19}$ The Consolidated Framework on Implementation Research (CFIR) identified five key aspects of implementation that influence intervention outcomes. ${ }^{20}$ These relate to characteristics of the intervention itself, factors related to the context ('outer setting'), the implementers ('inner setting', including the partnership between national stakeholders and technical support providers), and the implementation process. Specific constructs within these can be systematically analysed to identify barriers and facilitators for successful implementation, and these may then be translated into questions that can be answered through research and used to refine plans, programmes, and policies to better address needs, gaps or inequalities. ${ }^{21}$

Thus, an investment case may identify a specific intervention as a cost-effective priority based on national data; implementation research can then indicate how this may impact population groups differently and suggest ways 
that the implementation process and supporting actions should be tailored. For illustration, the Better Health Programme (BHP) is a collaborative technical support programme supported by the UK Foreign Commonwealth Office.$^{22} \mathrm{BHP}$ is applying implementation science to identify which of the obesity prevention strategies identified elsewhere as successful will be effective and acceptable in Kuala Lumpur's poorest communities. 'Discrete choice experiments', 'knowledge, attitude and practices' surveys, interviews and focus groups are being used to elicit stakeholder needs, preferences and constraints to inform design, delivery and modification of interventions on how to enable healthier food and drink consumption and increase physical activity. Support to apply an implementation science lens to NCD plans can in the short-term bridge the divide between plans and implementation, employ available evidence in a contextrelevant manner, and in the medium-term build national capacity to apply the techniques.

The analysis presented in this paper: the need to put in place-specific components to strengthen national implementation of NCD strategies and programmes, and to provide tailored technical support to enable this, relates to two particular aspects that the CFIR identified as influential on implementation outcomes. Within the inner setting' (the national context for NCD implementation), the 'Structural Characteristics' of the lead organisation (government/ministry) includes its 'social architecture', age, maturity and size, and these characteristics can influence its ability to successfully implement policies and plans. Within the 'outer setting' (external influences that can encourage a government to act to address NCDs), 'Cosmopolitanism' describes the degree that an organisation is networked with other external organisations. Our contention is that the current status of underdevelopment of NCD capacity at national level (priority, funding, capacity) may combine with an absence of external technical support and thus create a cycle of poor implementation.

While perhaps politically unfashionable to highlight direct support needs, we contend that at the present time technical support is essential to empower national health providers and policy-makers to operationalise effective NCD strategies. Support is needed to develop three fundamental, interconnected building-blocks: investment cases, sustainable financing mechanisms and national NCD technical leadership; to employ implementation science to create actionable NCD solutions from national plans; and tailored guidance to maximise the impact of specific policies, programmes and system developments. In the complex world of global health organisations, there are various institutions, foundations and agencies that can provide components of the required support, depending on their technical capabilities in relation to specific issues, delivery capacity and infrastructure and relationships in different countries. Serious progress on SDG 3.4 in LMICs requires bilateral and multilateral donor organisations and philanthropic foundations to enable these implementation support partnerships.

Twitter Angela Jackson-Morris @angiembjm and Rachel Nugent @RachelNugent

Contributors AJ-M initiated the conceptual model. RN and AJ-M refined and further developed this. AJ-M and RN coproduced and revised the manuscript.

Funding The authors have not declared a specific grant for this research from any funding agency in the public, commercial or not-for-profit sectors.

Competing interests None declared.

Patient consent for publication Not required.

Provenance and peer review Not commissioned; externally peer reviewed.

Data availability statement All data relevant to the study are included in the article or uploaded as supplementary information.

Open access This is an open access article distributed in accordance with the Creative Commons Attribution Non Commercial (CC BY-NC 4.0) license, which permits others to distribute, remix, adapt, build upon this work non-commercially, and license their derivative works on different terms, provided the original work is properly cited, appropriate credit is given, any changes made indicated, and the use is non-commercial. See: http://creativecommons.org/licenses/by-nc/4.0/.

\section{ORCID iDs}

Angela Jackson-Morris http://orcid.org/0000-0001-8348-7077

Rachel Nugent http://orcid.org/0000-0001-6421-9077

\section{REFERENCES}

1 World Health Organization. World health statistics 2020: monitoring health for the sustainable development goals. Available: https:// apps.who.int/iris/bitstream/handle/10665/332070/9789240005105eng.pdf?ua $=1$

2 World Health Organization. Assessing national capacity for the prevention and control of noncommunicable diseases: report of the 2019 global survey, 2020. Available: https://www.who.int/ publications/i/item/ncd-ccs-2019

3 World Health Organisation. It's time to walk the talk. WHO Independent High Level Commission on Non-Communicable Diseases Final report 2020:8.

4 Hutchinson B, Small R, Acquah K, et al. The investment case as a mechanism for addressing the Ncd burden: evaluating the NCD institutional context in Jamaica, and the return on investment of select interventions. PLoS One 2019;14:e0223412.

5 Nugent R, Bertram MY, Jan S, et al. Investing in non-communicable disease prevention and management to advance the sustainable development goals. Lancet 2018;391:2029-35

6 UN Interagency Taskforce on NCDs. Investing in the prevention and control of non-communicable diseases for sustainable development: countries discussed the role of investment cases, 2019. Available: https://www.who.int/ncds/un-task-force/october2019-investmentcase/en/

7 Webb D, Small R. Power dynamics, capacities and incentives that frame the implementation of ncd policies: lessons learned from conducting institutional and context analyses. presentation slides at the American public health association conference 2019.

8 World Health Organisation. Global NCD investment case encouraged the Norwegian Government's development of its NCD strategy and funding. Personal communication 2020.

9 Nugent R, Hutchinson B, Spencer GJ, et al. Studying investment in tobacco control in low- and middle- income countries, 2019. Available: https://www.rti.org/impact/studying-investment-tobaccocontrol-Imics

10 World Health Organization. Launch of NCD investment case in Armenia. website report, 2019. Available: https://www.who.int/ncds/ un-task-force/investment-case-missions/armenia-may-2019/en/

11 Rheeney A. The cost of tobacco use on a nation. The Samoa observer, editorial

12 Mensah J, Korir J, Nugent R, et al. World bank group working paper: combating noncommunicable diseases in Kenya: an investment case, 2020. Available: https://openknowledge.worldbank.org/handle/ 10986/33539

13 World Health Organisation Global Co-ordination Mechanism. Final report and recommendations from the Working Group on ways and means of encouraging Member States and non-State actors to realize the commitment included in paragraph 45(d) of the Political Declaration of the High-level Meeting of the United Nations General 
Assembly on the Prevention and Control of Non-communicable Diseases, 2018. Available: https://www.who.int/global-coordinationmechanism/working-groups/final_5_1with_annexes6may16.pdf?ua=1

14 World Health Organisation. Best buys and other recommended interventions for the prevention and control of noncommunicable diseases, 2017. Available: https://www.who.int/ncds/management/ best-buys/en

15 World Health Organisation. WHO steps surveillance manual. The who stepwise approach to non-communicable disease risk factor surveillance, 2017. Available: https://www.who.int/ncds/surveillance/ steps/manual/en/

16 Bollyky TJ, Templin T, Cohen M, et al. The relationships between Democratic experience, adult health, and cause-specific mortality in 170 countries between 1980 and 2016: an observational analysis. Lancet 2019;393:1628-40.

17 International Development Research Center. Tobacco Tax reforms to support economic development in West Africa, 2018. Available: https://www.idrc.ca/en/research-in-action/tobacco-tax-reformspromote-economic-development-west-africa
18 Philanthropies B. Accelerating the worldwide movement to reduce tobacco use. fall, 2011. Available: https://www.bbhub.io/dotorg/ sites/2/2014/04/BloombergPhilanthropies2011TobaccoReport.pdf

19 National Institute for Health - Fogarty International Center. Toolkit Part 1: implementation science methodologies and frameworks. Available: https://www.fic.nih.gov/About/center-global-healthstudies/neuroscience-implementation-toolkit/Pages/methodologiesframeworks.aspx [Accessed 27 May 2020].

20 Damschroder LJ, Aron DC, Keith RE, et al. Fostering implementation of health services research findings into practice: a consolidated framework for advancing implementation science. Implement Sci 2009;4:50.

21 Peters DH, Peters MA, Wickramasinghe K, et al. Asking the right question: implementation research to accelerate national noncommunicable disease responses. BMJ 2019;365:I1868.

22 UK Government. Global better health programme. Available: https://www.gov.uk/government/publications/better-healthprogramme 